\title{
Split course palliative radiotherapy for advanced lung cancer with 3D planning based analysis of outcome: a retrospective review
}

\author{
Andrew R. Bruggeman^, Reith R. Sarkar, Grace Sora Ahn^, Emily I. Fuster, Anna Dornisch, \\ Andrew B. Sharabi, James D. Murphy, Ajay P. Sandhu \\ Department of Radiation Medicine and Applied Sciences, University of California San Diego, La Jolla, CA, USA \\ Contributions: (I) Conception and design: AP Sandhu; (II) Administrative support: AR Bruggeman, GS Ahn; (III) Provision of study materials or \\ patients: AR Bruggeman, RR Sarkar; (IV) Collection and assembly of data: RR Sarkar, GS Ahn, EI Fuster; (V) Data analysis and interpretation: A \\ Dornisch, GS Ahn, EI Fuster; (VI) Manuscript writing: All authors; (VII) Final approval of manuscript: All authors. \\ Correspondence to: Andrew R. Bruggeman, MD. Department of Radiation Medicine and Applied Sciences, University of California San Diego, 3960 \\ Health Sciences Drive, La Jolla, CA 92093, USA. Email: abruggeman@ucsd.edu.
}

Background Durable palliation of advanced lung cancer is a common objective for radiation oncologists. However, there is no consensus on how to deliver the radiation course. Herein we report our experience of using split course radiotherapy and our assessment of outcomes based on planning from three-dimensional (3D) simulation before each treatment course.

Methods: All lung cancer patients from 2006-2020 were identified. Of these, 52 patients received a split course treatment of 50-60 Gy in 18-25 fractions intended to provide durable palliation for disease not amenable to curative therapy. Treatment involved 3D planning with repeat computed tomography (CT) simulation prior to the second course. Survival and symptomatic response were analyzed via chart review. We categorized rapid responders versus non-rapid responders from the initial radiation course based on $\geq 30 \%$ gross tumor volume (GTV) reduction at the second CT simulation. We evaluated the impact of response on overall survival and palliative response.

Results: Among our cohort treated with split course palliative radiotherapy, 33 (63\%) had a rapid response to initial treatment. There was no difference in survival between groups [hazard ratio $(\mathrm{HR})=1.30, \mathrm{P}=0.47$ ] There was no significant difference in palliative response rates between rapid and non-rapid responders. On multivariable analysis, only female sex $(\mathrm{HR}=0.26, \mathrm{P}<0.01)$ and receipt of systemic therapy following radiotherapy $(\mathrm{HR}=0.19, \mathrm{P}<0.01$ ) were associated with improved survival.

Conclusions: There is currently significant practice pattern variability for palliative lung radiotherapy. Split course palliative radiation of 50-60 Gy in 18-25 fractions represents an option to consider for patients with advanced lung cancer who do not undergo definitive therapy and may benefit from a higher dose regimen. Our retrospective review suggests that rapid tumor response in a split course model does not predict survival or symptomatic response. Prospective studies are needed to further define which lung cancer patients may benefit from higher dose regimens.

Keywords: Palliative radiation; lung cancer; three-dimensional planning (3D planning); split course

Submitted Jun 15, 2021. Accepted for publication Oct 07, 2021.

doi: 10.21037/apm-21-1589

View this article at: https://dx.doi.org/10.21037/apm-21-1589

^ ORCID: Andrew R. Bruggeman, 0000-0003-4757-5461; Grace Sora Ahn, 0000-0001-6141-589X. 


\section{Introduction}

Lung cancer continues to be a leading cause of morbidity and mortality in the US and around the world. Lung cancer accounts for more annual deaths in the US than prostate, breast, colon and pancreatic cancer combined (1). Despite recent advances in lung cancer screening, the majority of new lung cancer diagnoses continue to be at advanced stage and with existing metastases (1). How to treat patients with radiotherapy who have advanced disease that is not amenable to curative intent therapies continues to be a challenge based on a conflicting body of evidence. Some studies have shown improved palliation with higher radiation doses (2) while others have shown equal palliation of symptoms and survival regardless of dose $(3,4)$.

Previously, the University of Rochester Medical Center reported retrospectively on their experience using a split course protracted radiation schedule that showed robust symptom control and a tolerable side effect profile (5). Their regimen included an initial treatment to 25 Gy in 10 fractions followed 2 weeks later by additional radiation to a more definitive cumulative radiation dose of 50-62 Gy for those who tolerated the initial course of palliation. They used distant progression and subjective decision making between patient and physician on whether to proceed with the second course of lung radiotherapy. The potential advantages of this treatment regimen are to increase the total biological effective dose (BED) to the tumor while allowing a break to mitigate toxicity associated with a longer course of treatment (6). The purpose of this current retrospective study was to characterize objective findings and help to clarify which patients may benefit from the second half of a split course regimen. All patients at our institution who were treated with split-course radiation receive a second computed tomography (CT) simulation and adjustment of the treatment gross tumor volume (GTV). Our goal with this review was to investigate if reduction in primary tumor size on repeat CT simulation could elucidate a population that may have a greater benefit from the second course of treatment. We present the following article in accordance with the Strengthening the Reporting of Observational Studies in Epidemiology (STROBE) reporting checklist (available at https://apm. amegroups.com/article/view/10.21037/apm-21-1589/rc) (7).

\section{Methods}

\section{Patient population and radiation technique}

After obtaining IRB approval (\#190568), we conducted a retrospective chart review within a single academic radiation oncology department. We initially identified all patients diagnosed with carcinoma of the lung between Jan $1^{\text {st }} 2006$ and Dec $31^{\text {st }} 2020$, who received radiation treatment in our department. Within this group we identified 52 patients who received palliative radiation for stage IV or locally advanced incurable disease using a split course treatment delivery regimen. The initial course of radiation consisted of 2 weeks (25-30 Gy in 10 fractions) of radiation to the thorax, followed by a second course (25-30 Gy in 815 fractions) 2-3 weeks later. All patients had a CT simulation before the initial treatment and again before the second half of the split course. Radiotherapy planning included a physician-delineated GTV for each CT simulation scan. Target volumes were then utilized to ensure a 1.5$2 \mathrm{~cm}$ margin on gross disease with radiotherapy external beam fields adjusted according to anatomic location of the tumor. This most commonly consisted of two opposing anterior-posterior fields for the initial course and oblique fields (if deemed clinically necessary) to avoid exceeding spinal cord dose constraints for the second course. All patients were treated with palliative intent. Patients were not eligible for curative intent due to metastatic disease at presentation, inoperable advanced stage III disease, poor performance status, and/or patient preference.

Individual consent for this retrospective analysis was waived in accordance with HIPAA Privacy rule, 45 CFR 164 section 512(I) and satisfied criteria for waiver of individual authorization. The study was conducted in accordance with the Declaration of Helsinki (as revised in 2013).

\section{Data collection}

Baseline key patient characteristics including age, sex, smoking status, stage, histology, and any administration of chemotherapy prior to or following treatment were obtained from the electronic medical record. Additionally, key dates including date of diagnosis, date of initial and subsequent CT scan, and date of death were recorded. The three-dimensional (3D) tumor volume, as measured by the physician-delineated GTV, for the initial and subsequent CT scan were recorded. Total radiotherapy dose and fractionation were also recorded. Charts were reviewed to assess for recurrence and survival data. For the purposes of this study, we defined "responders" as a $\geq 30 \%$ decrease in GTV from initial CT simulation to follow-up scan and "non-responders" as those with $<30 \%$ decrease in GTV. This delineation point was used based upon the RECIST 
criteria of a partial response (8). Additionally, we assessed for documented symptoms of hemoptysis, chest pain, shortness of breath, or cough and whether these improved at post-treatment follow-up. Patients who had none of these symptoms at follow-up were considered to have a complete response and those with any improvement in symptoms were considered to have a partial response. Patients were only included in the cohort if they had confirmed non-small cell lung cancer (NSCLC). Patients lost to follow-up were not included and readjusted in separate analyses.

\section{Statistical analysis}

Summary statistics for patient demographic and clinical variables are reported in Table 1. Baseline continuous data were compared with $t$-tests. Categorical data were compared with Fisher's exact tests. We analyzed the impact of treatment response on survival outcome with KaplanMeier plots and multivariable Cox proportional hazard models. Survival was measured from the date of start of radiation through death with censoring at last followup. Symptoms were compared pre- and post-treatment using a Fisher's exact test. Additionally, we performed a multivariable analysis to determine if any additional clinical variables that were recorded were associated with survival. Variables assessed included age, sex, smoking status, cancer stage (at time of treatment), histology, and receipt of systemic therapy. All statistical analyses were performed with statistical software SAS Enterprise Guide (v.7.1; SAS Institute Inc., Cary, NC, USA).

\section{Results}

The sample size included 52 patients with primary lung cancer. Mean age was $68.9 \pm 12.9$ years with a distribution of $18(35 \%)$ women and $34(65 \%)$ men. The most common histologies were adenocarcinoma $(n=23,44 \%)$, squamous cell carcinoma $(\mathrm{n}=18,35 \%)$, and "NSCLC, other" $(\mathrm{n}=11$, $21 \%$ ) which consisted of NSCLC not otherwise specified, large cell carcinoma, poorly/undifferentiated carcinoma, and mucin-producing histologies. One patient with presumed NSCLC was excluded from the cohort due to lack of tissue sampling. Most were stage III $(n=14,27 \%)$ or IV ( $\mathrm{n}=38,73 \%)$ NSCLC at the time of treatment. Many patients received systemic therapies $(\mathrm{n}=25,48 \%)$ with 14 (27\%) receiving systemic therapy prior to radiation and 20 (38\%) after radiation. Among our cohort of patients treated with split course palliative radiotherapy, 33 (63\%) were found to have a rapid response to initial treatment and 19 (37\%) were classified as non-rapid responders. Examples of GTV in a rapid responder and a non-rapid responder are demonstrated in Figure 1. Baseline characteristic variables were compared between rapid responders and non-rapid responders, and there were no statistically significant differences between groups at baseline (Table 1).

Radiation was delivered with 25-30 Gy in 10 fractions, followed by a 2-3 week break with an additional 2.5-30 Gy delivered in $1-15$ additional fractions after a repeat $3 \mathrm{D}$ CT simulation. Most patients received a total of 50-55 Gy in $18-25$ fractions $(\mathrm{n}=43,83 \%)$ with 55 Gy in 20 fractions $(\mathrm{n}=32,62 \%)$ representing the most common treatment regimen. All patients included in this retrospective review completed their initial treatment course. Four patients started but did not complete the second half of their split course due to symptom progression or patient preference. The number of patients who were stopped at a dose of $<45 \mathrm{~Gy}$ in the responder group $(\mathrm{n}=2,6 \%)$ and the nonresponder group $(n=2,10.5 \%)$ were well balanced. Three patients did not complete treatment due to disease progression/death. One patient (in the responder group) did not complete treatment due to personal preference to discontinue treatment.

We also assessed symptomatic response to treatment and found no significant difference between rapid responders and non-rapid responders in terms of symptom improvement. There appeared to be a trend toward a higher complete symptomatic response in rapid responders $(\mathrm{n}=8$, $24 \%) v s$. non-rapid responders $(\mathrm{n}=2,10.5 \%)$ though this difference was not statistically significant $(\mathrm{P}=0.19)$. There was no difference in number of patients experiencing any symptomatic response to treatment between rapid and nonrapid responders $(73 \%$ vs. $77 \%, \mathrm{P}=0.69)$.

A Kaplan-Meier survival estimate for the patient cohorts demonstrated no difference in survival between rapid responders and non-rapid responders $(\mathrm{P}=0.73$, see Figure 2). All patients were followed until death or last available follow up (3 patients alive or with uncertain date of death and were censored at time of last follow up). Median survival was 8 months among rapid responders and 5.3 months among non-rapid responders. Average follow up time among all patients was 10 months. Among other clinical variables, female sex [hazard ratio (HR) $=0.26, \mathrm{P}<0.01]$ and receipt of systemic therapy following radiotherapy $(\mathrm{HR}=0.19, \mathrm{P}<0.01)$ were associated with improved survival outcome. Additionally, patients with stage IIIA or IIIB disease had improved survival compared 
Table 1 Patient baseline demographics and clinical variables

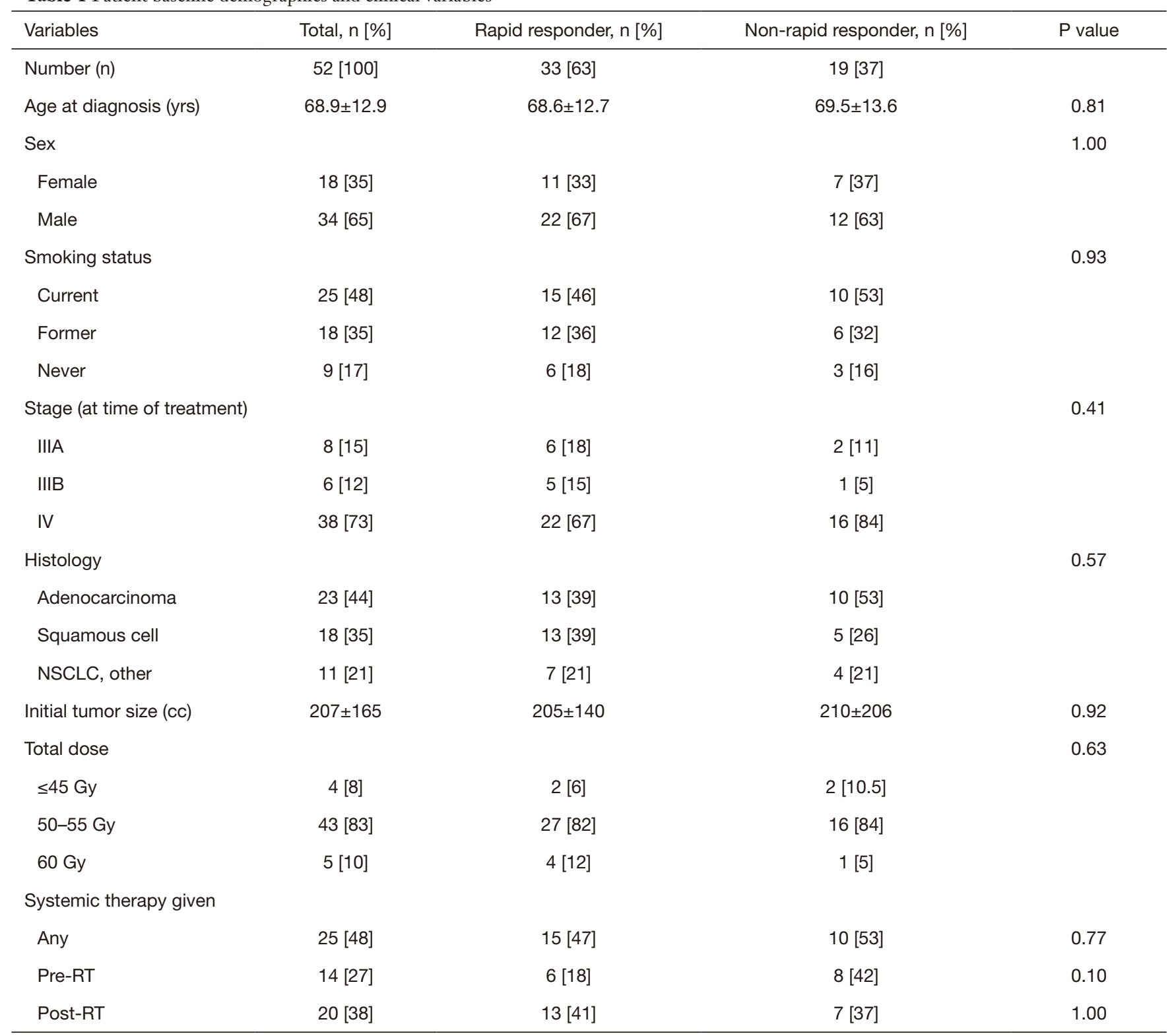

Difference in proportions evaluated with Fisher's exact test for categorical data and $t$-test analysis for continuous data. Continuous variables displayed as mean \pm standard deviation. Categorical variables displayed as total number (percentage). Division of baseline characteristics of patients based on rapid versus non-rapid response to split course palliative radiotherapy. NSCLC, non-small cell lung cancer; $\mathrm{RT}$, radiotherapy.

to those with stage IV disease (Table 2).

\section{Discussion}

There is a need for further clarity in how to best treat lung cancer with palliative intent. Palliative radiotherapy represents up to $40 \%$ of all radiation treatments and lung cancer represents one-third of these (9). When delivered to improve symptoms, palliative lung radiotherapy can improve hemoptysis, cough, chest pain, and dyspnea (10). Although the palliative benefit of lung radiotherapy is clear, the ideal treatment course based on prior literature is less clear $(6,11)$. This has resulted in significant disparity in terms of practice patterns for palliative treatment of lung 


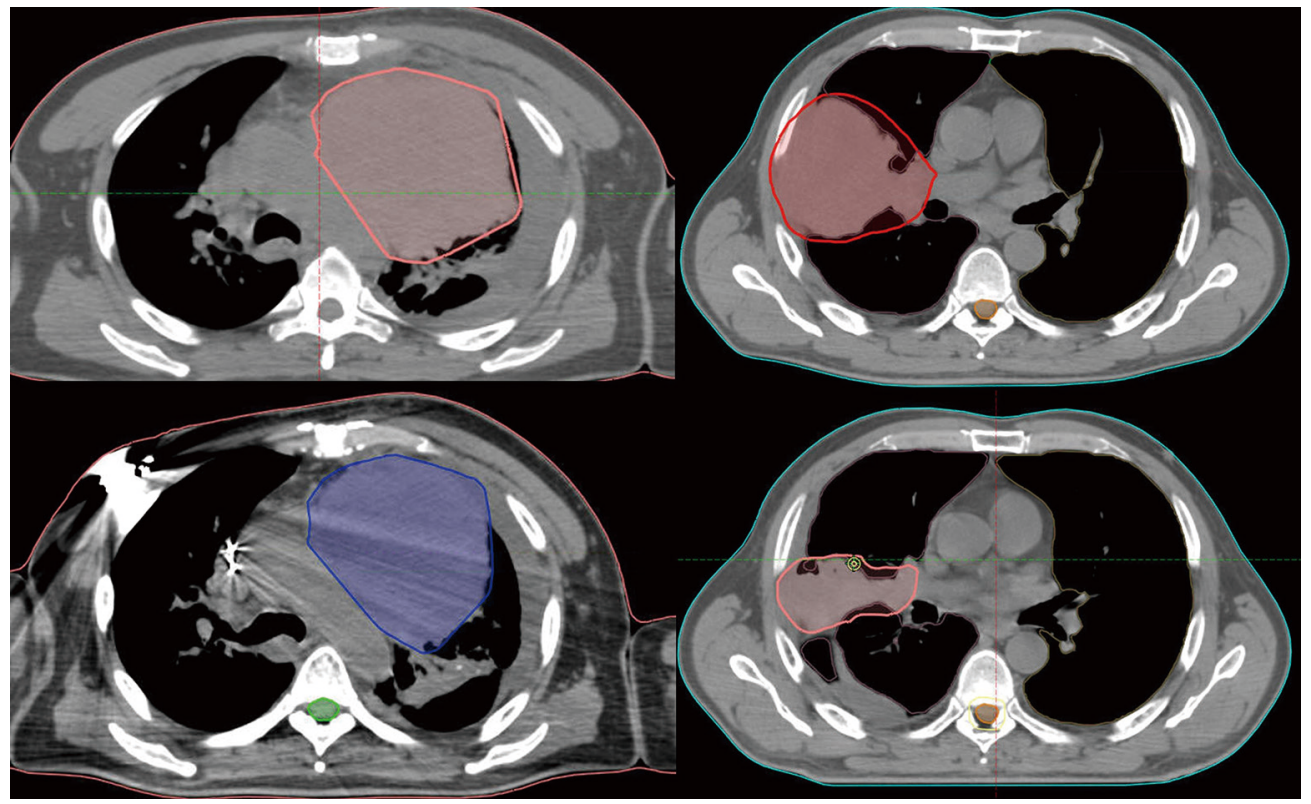

Figure 1 Representative GTVs. The case on the left represents a non-responder. In this case, GTV shrunk from 808 (top: pink) to 805 cc ${ }^{3}$ (bottom: blue). On the right is a representative GTV in a rapid responder. In this case, GTV shrunk from 415 (top: red) to $73 \mathrm{cc}^{3}$ (bottom: pink). GTV, gross tumor volume.

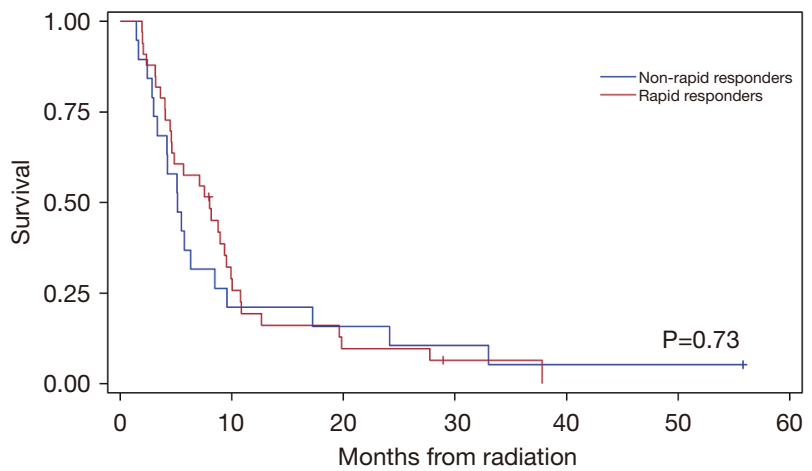

Figure 2 Kaplan-Meier plot for survival between rapid and nonrapid responders as defined by repeat $\mathrm{CT}$ simulation showing a $\geq 50 \%$ volume reduction. CT, computed tomography.

cancer (12).

Palliative radiation has been a mainstay of treatment in these advanced cancer patients for symptomatic disease progression and metastatic disease. However, the exact nature of radiation treatment continues to be redefined. Whether longer course protracted treatment schedules for durable palliation with a higher BED offer any advantage over shorter course palliative treatments is unclear. Randomized controlled trials comparing different regimens for alleviating thoracic symptoms have reported contradictory results with some showing improved palliation with a higher BED (2) and others with equal palliation of symptoms and survival $(3,4)$. Because of conflicting data, a meta-analysis of 13 randomized trials was published in 2013 demonstrating an improvement in overall symptom burden and a 1-year overall survival advantage for treatments delivered to a BED10 $>35$ Gy (however, this survival advantage was lost at 2 years) (6). In contrast to this, a Cochrane review in 2015 showed no difference in survival or palliation of symptoms with higher dose regimens (11). As a result of this conflicting body of evidence, there is significant variability among practice worldwide. A practice patterns survey demonstrated that $50 \%$ of patients in the United States and $25 \%$ of patients globally receive highdose palliative radiotherapy (>10 fractions of treatment) (12). Based on the body of available evidence there is reason to believe that there may be a group of patients that would benefit from a higher dose regimen; however, determining which patients could potentially benefit from a higher BED is not readily apparent.

We believe that the split course of palliative lung radiotherapy in our study represents a reasonable option to consider for patients with locally advanced or metastatic lung cancer who are not candidates for definitive treatment (5). 
Table 2 Multivariable Cox regression analysis of patients treated with split course palliative radiotherapy

\begin{tabular}{|c|c|c|c|}
\hline Variables & $\mathrm{HR}$ & $95 \%$ confidence interval & $P$ value \\
\hline Age & 1.02 & $(0.98,1.06)$ & 0.26 \\
\hline \multicolumn{4}{|l|}{ Sex } \\
\hline Male & (Ref) & & \\
\hline Female & 0.26 & $(0.11,0.63)$ & $<0.01$ \\
\hline \multicolumn{4}{|l|}{ Smoking status } \\
\hline Never & (Ref) & & \\
\hline Current & 1.26 & $(0.45,3.52)$ & 0.65 \\
\hline Former & 2.01 & $(0.72,5.61)$ & 0.18 \\
\hline \multicolumn{4}{|l|}{ Stage } \\
\hline IV & (Ref) & & \\
\hline IIIA & 0.33 & $(0.12,0.91)$ & 0.03 \\
\hline IIIB & 0.27 & $(0.08,0.92)$ & 0.04 \\
\hline \multicolumn{4}{|l|}{ Histology } \\
\hline Adenocarcinoma & (Ref) & & \\
\hline Squamous cell & 0.82 & $(0.37,1.81)$ & 0.62 \\
\hline NSCLC, other & 2.8 & $(1.12,6.99)$ & 0.03 \\
\hline \multicolumn{4}{|l|}{ Systemic therapy } \\
\hline Pre-RT & 0.82 & $(0.39,1.71)$ & 059 \\
\hline Post-RT & 5.36 & $(2.08,13.79)$ & $<0.01$ \\
\hline Rapid response to RT & 1.30 & $(0.64,2.62)$ & 0.47 \\
\hline
\end{tabular}

Impact of treatment response on survival outcome evaluated with multivariable Cox proportional hazard models. HR, hazard ratio; NSCLC, non-small cell lung cancer; RT, radiotherapy.

The advantage of this option is that it allows a higher BED in the palliative setting which may allow for improved outcomes, while mitigating the potential toxicity associated with a longer course of therapy. At our institution we have treated 52 patients with primary lung cancer not amenable to curative treatment with a split course from 2006 to 2020. This has most commonly consisted of 30 Gy in 10 fractions followed by a 2-3 week break with an additional 25-30 Gy in $10-15$ additional fractions with a repeat CT simulation prior to the second course of treatment. Based on the results of our retrospective study, we did not find a survival benefit associated with a rapid GTV response to the initial half of a split palliative treatment course. The only variables in our retrospective cohort of patients which were associated with improved survival were female sex, receipt of systemic therapy following palliative radiotherapy, and earlier stage disease which is consistent with the general lung cancer literature $(13,14)$. However, while not statistically significant, there appeared to be a trend for an improved complete symptomatic response among patients who had a rapid response to therapy.

There are several possible reasons that we did not see a difference in survival between the two groups. The first is that the study was likely underpowered to detect a significant difference between the two groups. Secondly, patients with advanced lung cancer have aggressive disease and are likely to harbor competing risk of distant failure which would have a significant impact on survival and likely limit the impact of local thoracic disease control on overall survival time. Thirdly, one could hypothesize that patients who had a rapid response to treatment may not be likely to benefit from the second half of the split course since they already obtained a good response from the first half of treatment. It is possible that the poor responders were the ones more likely to benefit from the second half of treatment. In this scenario, we speculate that the second half of treatment may have helped mitigate what may have otherwise been a worse survival in that cohort. Regarding the lack of differences in symptomatic improvement between the groups, this result is not particularly surprising given the small sample size as well as the fact that many large randomized controlled trials have failed to see a palliative benefit to higher biologic doses $(3,4)$.

We acknowledge that there are several limitations to this review. Primarily, this is a retrospective single institution study which may not be generalizable to other lung cancer patients. Additionally, our cohort of 52 patients is small; however, we believe this sample represents the largest published cohort of patients with repeat 3D CT simulation data in the palliative lung setting. Additionally, the treatment break may draw criticism in a study that looks to assess overall survival due to the known detriment of treatment breaks to local control and disease specific survival in patients receiving curative intent RT for NSCLC (15); however, given that the intent of treatment is palliative, one must weigh the potential for improvement in symptoms and survival with potential for toxicity, which can be mitigated with a treatment break.

In summary, based on our retrospective review of patients treated with a split course of palliative lung radiotherapy, we did not observe a difference in survival between rapid responders and non-rapid responders (HR $=1.3, \mathrm{P}=0.47)$. There were no differences in palliative 
response to treatment $(\mathrm{P}=0.69)$. However, a trend toward improved complete symptomatic response rates among rapid responders ( $24 \%$ vs. $11 \%$ ) was observed, though this was not statistically significant $(\mathrm{P}=0.19)$. Further research is needed to define if a specific cohort of lung cancer patients may benefit from a higher dose of palliative lung radiotherapy, especially given advances in systemic therapy for lung cancer which can improve overall survival.

\section{Acknowledgments}

This work was previously presented as an Abstract at the 26th Annual Meeting of the American College of Radiation Oncology March 17-19, 2016. Additionally, this work received technical support by Vinit Nalawade during final preparation for submission.

Funding: None.

\section{Footnote}

Reporting Checklist: The authors have completed the STROBE reporting checklist. Available at https://apm. amegroups.com/article/view/10.21037/apm-21-1589/rc

Data Sharing Statement: Available at https://apm.amegroups. com/article/view/10.21037/apm-21-1589/dss

Conflicts of Interest: All authors have completed the ICMJE uniform disclosure form (available at https://apm. amegroups.com/article/view/10.21037/apm-21-1589/ coif). ARB serves as an advisor for Courage Health. RRS and JDM report personal fees from Boston Consulting Group, outside the submitted work. ABS reports University research funding and honoraria from Pfizer and Varian Medical Systems, consultant fees from Astrazeneca and Jounce Therapeutics, and other fees from Raysearch and Merck. ABS is the scientific founder and has an equity interest in Toragen Inc. outside the submitted work. The terms of this arrangement have been reviewed and approved by the University of California, San Diego in accordance with its conflict of interest policies. The other authors have no conflicts of interest to declare.

Ethical Statement: The authors are accountable for all aspects of the work in ensuring that questions related to the accuracy or integrity of any part of the work are appropriately investigated and resolved. IRB approval (\#190568) was obtained by the institution's Human
Research Protections Program. Individual consent for this retrospective analysis was waived in accordance with HIPAA Privacy rule, 45 CFR 164 section 512(I) and satisfied criteria for waiver of individual authorization. The study was conducted in accordance with the Declaration of Helsinki (as revised in 2013).

Open Access Statement: This is an Open Access article distributed in accordance with the Creative Commons Attribution-NonCommercial-NoDerivs 4.0 International License (CC BY-NC-ND 4.0), which permits the noncommercial replication and distribution of the article with the strict proviso that no changes or edits are made and the original work is properly cited (including links to both the formal publication through the relevant DOI and the license). See: https://creativecommons.org/licenses/by-nc-nd/4.0/.

\section{References}

1. Siegel RL, Miller KD, Jemal A. Cancer statistics, 2016. CA Cancer J Clin 2016;66:7-30.

2. Teo P, Tai TH, Choy D, et al. A randomized study on palliative radiation therapy for inoperable non small cell carcinoma of the lung. Int J Radiat Oncol Biol Phys 1988;14:867-71.

3. Abratt RP, Shepherd LJ, Salton DG. Palliative radiation for stage 3 non-small cell lung cancer--a prospective study of two moderately high dose regimens. Lung Cancer 1995;13:137-43.

4. Sundstrøm S, Bremnes R, Aasebø U, et al. Hypofractionated palliative radiotherapy (17 Gy per two fractions) in advanced non-small-cell lung carcinoma is comparable to standard fractionation for symptom control and survival: a national phase III trial. J Clin Oncol 2004;22:801-10.

5. Metcalfe SK, Milano MT, Bylund K, et al. Split-course palliative radiotherapy for advanced non-small cell lung cancer. J Thorac Oncol 2010;5:185-90.

6. Fairchild A, Harris K, Barnes E, et al. Palliative thoracic radiotherapy for lung cancer: a systematic review. In: Database of Abstracts of Reviews of Effects (DARE): Quality-assessed Reviews. York: Centre for Reviews and Dissemination (UK), 2008.

7. von Elm E, Altman DG, Egger M, et al. The Strengthening the Reporting of Observational Studies in Epidemiology (STROBE) Statement: guidelines for reporting observational studies. Int J Surg 2014;12:1495-9.

8. Eisenhauer EA, Therasse P, Bogaerts J, et al. New response 
evaluation criteria in solid tumours: revised RECIST guideline (version 1.1). Eur J Cancer 2009;45:228-47.

9. Vinod SK. International patterns of radiotherapy practice for non-small cell lung cancer. Semin Radiat Oncol 2015;25:143-50.

10. Langendijk JA, ten Velde GP, Aaronson NK, et al. Quality of life after palliative radiotherapy in non-small cell lung cancer: a prospective study. Int J Radiat Oncol Biol Phys 2000;47:149-55

11. Stevens R, Macbeth F, Toy E, et al. Palliative radiotherapy regimens for patients with thoracic symptoms from nonsmall cell lung cancer. Cochrane Database Syst Rev 2015;1:CD002143.

12. Rodrigues G, Macbeth F, Burmeister B, et al. International practice survey on palliative lung radiotherapy: third international consensus workshop on palliative

Cite this article as: Bruggeman AR, Sarkar RR, Ahn GS, Fuster EI, Dornisch A, Sharabi AB, Murphy JD, Sandhu AP. Split course palliative radiotherapy for advanced lung cancer with 3D planning based analysis of outcome: a retrospective review. Ann Palliat Med 2022;11(2):423-430. doi: 10.21037/apm21-1589 radiotherapy and symptom control. Clin Lung Cancer 2012;13:225-35.

13. Marino P, Pampallona S, Preatoni A, et al. Chemotherapy vs supportive care in advanced non-small-cell lung cancer. Results of a meta-analysis of the literature. Chest 1994;106:861-5.

14. Visbal AL, Williams BA, Nichols FC 3rd, et al. Gender differences in non-small-cell lung cancer survival: an analysis of 4,618 patients diagnosed between 1997 and 2002. Ann Thorac Surg 2004;78:209-15; discussion 215.

15. Cox JD, Pajak TF, Asbell S, et al. Interruptions of highdose radiation therapy decrease long-term survival of favorable patients with unresectable non-small cell carcinoma of the lung: analysis of 1244 cases from 3 Radiation Therapy Oncology Group (RTOG) trials. Int J Radiat Oncol Biol Phys 1993;27:493-8. 